\title{
Dogs infected with the blood trypomastigote form of Trypanosoma cruzi display an increase expression of cytokines and chemokines plus an intense cardiac parasitism during acute infection
}

\author{
Sheler Martins de Souza ${ }^{a}$, Paula Melo de Abreu Vieira ${ }^{a, b}$, Bruno Mendes Roatt ${ }^{a}$, \\ Levi Eduardo Soares Reis ${ }^{\mathrm{a}, \mathrm{c}}$, Kátia da Silva Fonseca ${ }^{\mathrm{a}}$, Nívia Carolina Nogueira ${ }^{\mathrm{a}}$, \\ Alexandre Barbosa Reis ${ }^{\mathrm{a}, \mathrm{c}}$, Washington Luiz Tafuri ${ }^{\mathrm{a}, 1}$, Cláudia Martins Carneiro ${ }^{\mathrm{a}, \mathrm{c}, *}$ \\ a Laboratório de Imunopatologia, Núcleo de Pesquisas em Ciências Biológicas, Universidade Federal de Ouro Preto, Ouro Preto, Minas Gerais, Brazil \\ b Departamento de Ciências Biológicas, Instituto de Ciências Exatas e Biológicas, Universidade Federal de Ouro Preto, Ouro Preto, Minas Gerais, Brazil \\ ${ }^{\mathrm{c}}$ Laboratório de Pesquisas Clínicas, Departamento de Análises Clínicas, Escola de Farmácia, Universidade Federal de Ouro Preto, Ouro Preto, Minas Gerais, \\ Brazil
}

\section{A R T I C L E I N F O}

\section{Article history:}

Received 7 October 2013

Received in revised form 5 November 2013

Accepted 9 November 2013

Available online 7 December 2013

\section{Keywords:}

Trypanosoma cruzi

Chagas disease

Cytokines

Chemokines

Chemokine receptor

\begin{abstract}
A B S T R A C T
The recent increase in immigration of people from areas endemic for Chagas disease (Trypanosoma cruzi) to the United States and Europe has raised concerns about the transmission via blood transfusion and organ transplants in these countries. Infection by these pathways occurs through blood trypomastigotes (BT), and these forms of T. cruzi are completely distinct of metacyclic trypomastigotes (MT), released by triatomine vector, in relation to parasite-host interaction. Thus, research comparing infection with these different infective forms is important for explaining the potential impacts on the disease course. Here, we investigated tissue parasitism and relative mRNA expression of cytokines, chemokines, and chemokine receptors in the heart during acute infection by MT or BT forms in dogs. BT-infected dogs presented a higher cardiac parasitism, increased relative mRNA expression of pro-inflammatory and immunomodulatory cytokines and of the chemokines CCL3/MIP- $1 \alpha$, CCL5/RANTES, and the chemokine receptor CCR5 during the acute phase of infection, as compared to MT-infected dogs. These results suggest that infection with BT forms may lead to an increased immune response, as revealed by the cytokines ratio, but this kind of immune response was not able to control the cardiac parasitism. Infection with the MT form presented an increase in the relative mRNA expression of IL-12p40 as compared to that of IL-10 or TGF- $\beta 1$. Correlation analysis showed increased relative mRNA expression of IFN- $\gamma$ as well as IL-10, which may be an immunomodulatory response, as well as an increase in the correlation of CCL5/RANTES and its CCR5 receptor. Our findings revealed a difference between inoculum sources of $T$. cruzi, as vectorial or transfusional routes of $T$. cruzi infection may trigger distinct parasite-host interactions during the acute phase, which may influence immunopathological aspects of Chagas disease.
\end{abstract}

(C) 2013 Elsevier Ltd. All rights reserved.
Abbreviations: BT, blood trypomastigotes; GAPDH, glyceraldehyde-3-phosphate dehydrogenase; GPI, glycosylphosphatidylinositol; IFN- $\gamma$, interferon-gamma; IL-4, interleukin-4; IL-10, interleukin-10; IL-12, interleukin-12; MIP, macrophage inflammatory protein; MT, metacyclic trypomastigotes; NI, not infected; RA, right atrium; TGF- $\beta$, transforming growth factor $\beta$; UFOP, Universidade Federal de Ouro Preto.

* Corresponding author at: Laboratório de Imunopatologia, Núcleo de Pesquisas em Ciências Biológicas, ICEB II, Morro do Cruzeiro, Universidade Federal de Ouro Preto, Ouro Preto, MG, Brasil, CEP 35400-000, Brazil. Tel.: +55 21313559 1694; fax: +55213135591680.

E-mail addresses: carneirocm@gmail.com, claudiamartinscarneiro@gmail.com (C.M. Carneiro)

1 In Memoriam.

\section{Introduction}

American trypanosomiasis is a zoonosis caused by the flagellate protozoan Trypanosoma cruzi, known as Chagas disease (Chagas, 1909). In the early 1990s, regional control programs directed against domestic vectors were initiated in most of Latin American countries, and they led to a reduction of disease prevalence from 16-18 million people infected in 1990 to current estimates of approximately 7-8 million (WHO, 2013). However, in recent decades, Chagas disease has emerged in nonendemic areas due to migration of Latin Americans to regions such as North America and Europe, thus highlighting the transfusional transmission of Chagas disease (Jackson et al., 2010; Gascon et al., 2010; Strasen et al., 2013; Wallace et al., 2013). 
The parasite exists in at least three morphologically distinct stages. Epimastigotes proliferate in the invertebrate host and are released as metacyclic trypomastigotes (MT) in their feces. In the vertebrate host, amastigotes and blood trypomastigotes (BT) are the intracellular developmental and infective forms, respectively (Andrade and Andrews, 2005). Although, both MT and BT forms of T. cruzi are fully functional with respect to parasite-host interaction and/or target cell invasion, these two morphological forms differ in their surface molecules (Ramirez et al., 1993; Yoshida, 2006).

During ongoing T. cruzi infection, macrophages can induce proinflammatory cytokine production, such as interleukin-12 (IL-12), which in turn stimulates interferon-gamma (IFN- $\gamma$ ) delivered from innate immune cells, natural killer cells, or specific $\mathrm{T}$ lymphocytes. IFN- $\gamma$ functions in the activation of macrophages, amplifying the innate immune response, continuing the synthesis of proinflammatory cytokines, and performing effector functions through the production of reactive nitrogen intermediates, such as nitric oxide (Michailowsky et al., 2001; Ropert et al., 2002; Vivier et al., 2008). During infection by T. cruzi, immunomodulatory cytokines such as interleukin-10 (IL-10) and transforming growth factor $\beta$ (TGF- $\beta$ ) or type II interleukin-4 (IL-4) can help regulate the immune response to prevent the occurrence of intense cardiac inflammatory process (Soares et al., 2001; Costa et al., 2009). TGF- $\beta$, considered to be a modulator of immune response, may contribute to the recruitment of fibroblasts, an important step in the development of fibrosis (Gazzinelli et al., 1992; Hansen et al., 1998; Lijnen et al., 2000; Araujo-Jorge et al., 2002; Martin et al., 2007). Furthermore, chemokines such as CCL3/MIP- $1 \alpha$ (macrophage inflammatory protein $[\mathrm{MIP}]-1 \alpha)$ that are related to macrophage migration and CCL5/RANTES (regulated upon activation, normally expressed and secreted by T cells) are important during $T$. cruzi infection, facilitating $\mathrm{T}$ cell migration to the site of the infection. CCR5 receptor plays a role in the functions of both chemokines (Rottman et al., 1997; Cunha-Neto et al., 1998; Kaufmann et al., 2001; Mack et al., 2001; Teixeira et al., 2002).

Our research group has been evaluating the natural history of the canine model of Chagas disease when inoculated with MT or BT forms. Some differences were found, such as infectivity, immune response, and pathogenicity (Bahia et al., 2002). Our studies have also revealed that MT and BT infections are associated with distinct parasitological and serological profiles (Coura-Vital et al., 2008). Moreover, these source-specific inocula promote higher levels of circulating $\mathrm{CD}^{+} \mathrm{T}$ lymphocytes when dogs were infected by the MT form (Carneiro et al., 2007). We also demonstrated that the levels of serum nitric oxide and iNOS expression in the heart were increased in the MT group as compared to dogs infected with the BT form (Vieira et al., 2009).

In the present study, we investigated infection by different infective forms of $T$. cruzi and their consequences in the cytokine and chemokine profiles as well as the cardiac parasite load in dogs experimentally infected with MT and BT forms. Our main goal was to evaluate the cytokines and chemokines, including the CCR5 chemokine receptor profile, during the course of acute Chagas disease. We also investigated the differences in cardiac parasitism between MT and BT forms employed in the experimental infection.

\section{Materials and methods}

Details of the study were approved by the Ethical Committee on Animal Research of the Universidade Federal de Ouro Preto (UFOP). All procedures were carried out in compliance with current Brazilian regulations relating to experimental biology and medicine as described in the guidelines issued by the Colégio Brasileiro de Experimentação Animal (COBEA, 2006). Study animals were maintained in the central animal facility at the UFOP, Minas Gerais, Brazil.

\subsection{Parasites, animals, and experimental infection}

MT and BT forms of the Berenice-78 T. cruzi strain (Lana and Chiari, 1986) were isolated, respectively, from nymphs of the vector Triatoma infestans and female Swiss Webster mice that had been previously infected in our laboratory. Before the beginning of the study, 12 mongrel dogs ( 6 males and 6 females) born in the kennel at UFOP, Minas Gerais, Brazil, were treated with anthelminthic drugs and immunized against more common canine infectious pathogens. Animals were maintained in quarantine for 16 weeks and received drinking water and a balanced commercial feed ad libitum. When the animals were 120 days of age, dogs were inoculated intraperitoneally with MT $(n=4)$ or BT $(n=4)$ forms of the Berenice-78 T. cruzi strain (2000 trypomastigotes/kg body weight), and the remaining 4 dogs were maintained uninfected as the not infected (NI) group. These dogs were euthanized at 42 days after infection.

\subsection{Extraction of total RNA, synthesis of first-strand cDNAs, and real-time $P C R$}

Fragment of right atrium (RA) was stored at $-80^{\circ} \mathrm{C}$ until required for RNA analysis. Total RNA was extracted by homogenizing approximately $20 \mathrm{mg}$ of tissue with $1 \mathrm{~mL}$ of TRIzol reagent (Invitrogen Brasil, São Paulo, SP, Brazil) in a rotor stator. The lysate was incubated at room temperature for $10 \mathrm{~min}$, mixed with chloroform $(200 \mu \mathrm{L})$ by tube inversion, and centrifuged at $12,000 \times \mathrm{g}$ for $10 \mathrm{~min}$ at $4{ }^{\circ} \mathrm{C}$. The aqueous phase was collected and RNA extraction continued using the SV Total RNA Isolation System (Promega, Madison, WI, USA) according to the recommendations of the manufacturer, which included a DNase treatment step. The concentration and quality of RNA obtained was determined with a spectrophotometer (Nanodrop, GE Healthcare Products, Piscataway, NJ, USA). For synthesis of the first cDNA, we used the High Capacity cDNA Reverse Transcription kit (PE Applied Biosystems, Foster City, CA, USA). Real-time PCR was performed on an ABI Prism 7500 DNA Sequence Detection System using $5 \mu \mathrm{L}$ of SYBR Green PCR Master Mix (PE Applied Biosystems, Foster City, CA, USA), $3 \mu \mathrm{L}$ of $2.5 \mu \mathrm{M}$ primers and $2 \mu \mathrm{L}$ of cDNA diluted at $1: 5$ carried out in a final volume of $10 \mu \mathrm{L}$.

To evaluate the gene expression of cytokines in RA, we used the primers listed in Table 1 and SYBR Green (Applied Biosystems). The analysis was performed in triplicate for all genes; the constitutive glyceraldehyde-3-phosphate dehydrogenase (GAPDH) present and results are expressed by the method $2^{-\Delta \mathrm{Ct}}=2^{-(\mathrm{Ct} \text { target gene }-\mathrm{Ct} \mathrm{GAPDH})}$.

\subsection{DNA extraction, real-time PCR, and T. cruzi standard calibration curve}

Samples of the RA and T. cruzi parasite were stored frozen at $-80^{\circ} \mathrm{C}$ for subsequent analyses. To calculate the standard curve of the parasite, $T$. cruzi epimastigotes $Y$ strain was cultured to reach a level of $1 \times 10^{8}$ parasites. Standard curves were generated from six serial dilutions in water $(1: 10)$ of DNA extracted from epimastigotes culture containing $1 \times 10^{8}$ parasites. Good laboratory practice was used to avoid DNA cross-contamination, and negative controls were included during all DNA extraction procedures and in performance of the molecular techniques. Total genomic DNA was extracted from approximately $30 \mathrm{mg}$ of the RA using Wizard Genomic DNA purification kits (Promega) according to the manufacturer's instructions. The concentration and quality of DNA obtained was determined with a spectrophotometer (Nanodrop, GE Healthcare Products). Each real-time PCR reaction was performed in $10 \mu \mathrm{L}$ containing $50 \mathrm{ng}$ of genomic DNA and $5 \mu \mathrm{L}$ of SYBR Green PCR Mastermix (Applied Biosystems). The primers for T. cruzi 
Table 1

Sequences of primers used for mRNA expression quantification by real-time PCR.

\begin{tabular}{ll}
\hline Gene & Nucleotide sequence $\left(5^{\prime} \rightarrow 3^{\prime}\right)^{\mathrm{a}}$ \\
\hline GAPDH & F: CTACCCACGGCAAATCC \\
& R: ACTCAGCACCAGCAT \\
IL-12p40 & F: CAGCAGAGAGGGTCAGAG TGG \\
& R: ACGACCTCGATGGGTAGG C \\
TNF- $\alpha$ & F: CGTCCATTCTTGCCCAAAC \\
& R: AGCCCTGAGCCTTAATT \\
IFN- $\gamma$ & F: TCAACCCCTTCTCGCCACT \\
& R: GCTGCCTACTTGGTCCCTGA \\
IL-4 & F: CACCTCCCAACTGATTCCAA \\
& R: CTCGCTGTGAGGATGTTCAA \\
IL-10 & F: AGAACCACGACCCAGACATC \\
& R: CCACCGCCTTGCTCTTATTC \\
TGF- $\beta 1$ & F: AGGATCTGGGCTGGAAGTG \\
& R: CGGGTTGTGCTGGTTGTA \\
CCL3/MIP-1 $\alpha$ & F: GTCTCCAAGCAGATTCCA \\
& R: CTGGTCTCAAAGCAGTCG \\
CCL5/RANTES & F: AATAAAAGCCTCCTCCATAAGT \\
CCR5 & R: TCAAGCTGAGAGGCCTGAAA \\
& F: TCCTTCTCCTGAGACCCTT \\
& R: CCCGACGAAAGCATAGAT \\
\hline
\end{tabular}

${ }^{a} \mathrm{~F}$, forward primer; $\mathrm{R}$, reverse primer.

repetitive DNA (TCZ-F 5'-GCTCTTGCCCACAMGGGTGC-3', where $\mathrm{M}=\mathrm{A}$ or $\mathrm{C}$ and TCZ R 5'-CCAAGCAGCGGATAGTTCAGG-3') amplify a 182-bp fragment (Cummings and Tarleton, 2003). Each 96-well reaction plate contained standard curve, previously generated, and negative controls. Negative controls consisted of a reaction with T. cruzi - specific primers without DNA and RA from NI dog. Each DNA sample was quantified in triplicate. To create a standard curve, a stock solution of $T$. cruzi DNA solution was obtained by extraction from $1 \times 10^{8}$ epimastigotes. Serial dilutions in water $(1: 10)$ of the DNA stock solution were performed to obtain the points of the curve spanning from the DNA equivalent of $1 \times 10^{6}$ to one parasite.

\subsection{Qualitative analysis by immunohistochemical}

After necropsy the fragments of the heart was sectioned, fixed in $10 \%$ buffered formalin ( $\mathrm{pH} 7.2$ ) and embedded in paraffin. Sections ( $4 \mu \mathrm{m}$ thick) were mounted on previously gelatinized glass slides and submitted to immunohistochemical technique.

\subsection{Statistical analyses}

Statistical analyses were performed using the Prism 5.0 software package (Prism Software, Irvine, CA, USA). Kruskal-Wallis and Dunn's post hoc tests were used to compare the different groups. The Mann-Whitney test and Spearman's rank correlation were used to compare the tissue parasitism between the infected groups and to investigate correlations between parasitism and relative mRNA expression of cytokines, chemokines, and CCR5 receptor. Values are expressed as medians \pm standard error. In all cases, differences were considered statistically significant when $p \leq 0.05$.

\section{Results}

\subsection{Cytokine mRNA expression profiles in dogs experimentally} infected with MT and BT forms

We observed a higher relative mRNA expression of the proinflammatory cytokine IL-12p40 in dogs infected with BT forms as compared with the NI group (Fig. 1A). Similar results were obtained

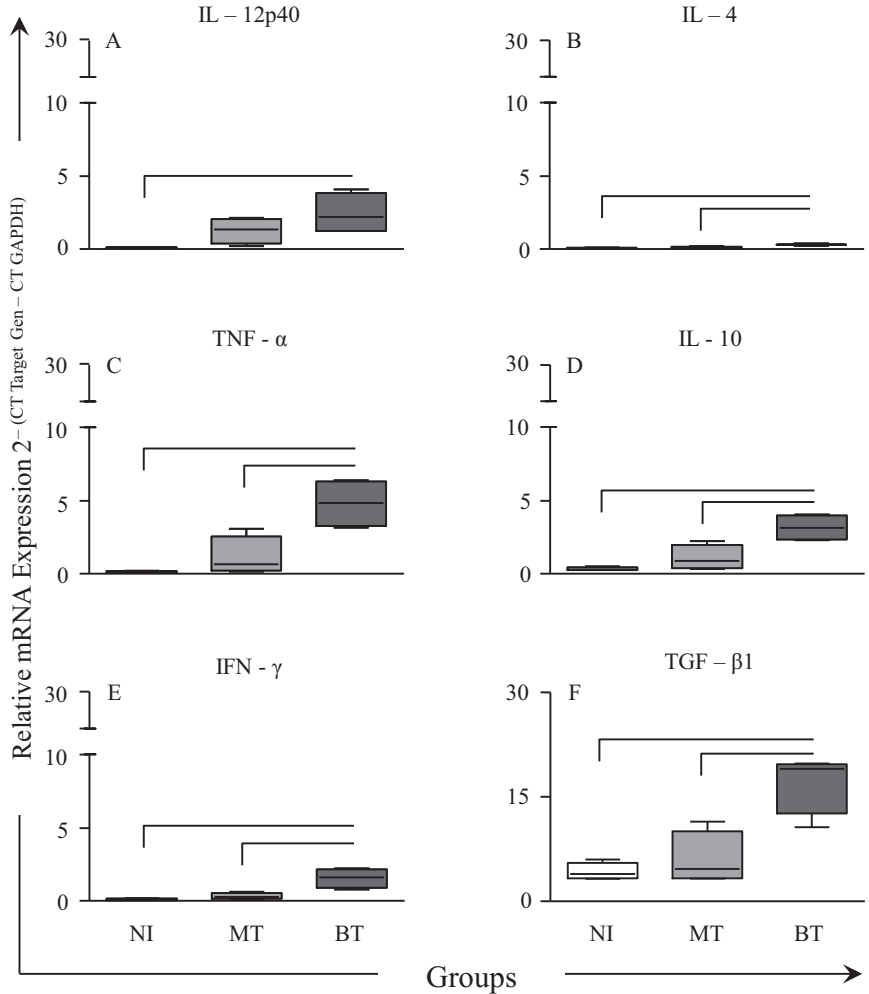

Fig. 1. The relative mRNA expression of pro-inflammatory, type II and immunomodulatory cytokines in right atrium of uninfected $(\mathrm{NI})$ dogs in comparison to acute canine infection with metacyclic (MT) or blood trypomastigote (BT) forms of Berenice-78 Trypanosoma cruzi strain. Significant differences $(p \leq 0.05)$ between groups are indicated by connecting lines.

for relative mRNA expression of TNF- $\alpha$ and IFN- $\gamma$, which were increased in animals infected with BT forms in relation to the $\mathrm{NI}$ and MT groups (Fig. 1C and E, respectively). Regarding the antiinflammatory cytokines (IL-4, IL-10, and TGF- $\beta 1$ ), we observed a higher expression of these cytokines in dogs infected with BT forms in relation to the NI and MT groups (Fig. 1B, D, and E).

The analysis of cytokine ratios showed significant differences among the infective forms of $T$. cruzi (Table 2). We observed an increased mRNA expression of IL-12p40 in relation to the immunomodulatory cytokines, IL-10 and TGF- $\beta 1$, in dogs infected with the MT form. In the dogs infected with the BT form, however, this increase occurred in the relative mRNA expression of TNF- $\alpha$ when compared with IL- 10 and TGF- $\beta 1$. With regard to the cytokine IFN- $\gamma$, an increase occurred only in relation to TGF- $\beta 1$ in the BT group.

Table 2

The ratios of mRNA expression of cytokines in the right atrium of dogs uninfected (NI) and those infected with metacyclic (MT) or blood (BT) trypomastigotes of Berenice-78 strain of Trypanosoma cruzi.

\begin{tabular}{lrll}
\hline Ratio & \multicolumn{1}{l}{ NI } & \multicolumn{1}{l}{ MT } & \multicolumn{1}{l}{ BT } \\
\hline IL-12p40/IL-10 & $0.341 \pm 0.049$ & $1.183 \pm 0.504^{*}$ & $0.811 \pm 0.476$ \\
IL-12p40/TGF- $\beta 1$ & $0.02 \pm 0.003$ & $0.210 \pm 0.112^{*}$ & $0.159 \pm 0.112$ \\
TNF- $\alpha /$ IL-10 & $0.384 \pm 0.116$ & $0.827 \pm 0.377$ & $1.633 \pm 0.757^{*}$ \\
TNF- $\alpha /$ TGF- $\beta 1$ & $0.029 \pm 0.008$ & $0.148 \pm 0.091$ & $0.313 \pm 0.185^{*}$ \\
IFN- $\gamma /$ IL-10 & $0.377 \pm 0.236$ & $0.369 \pm 0.154$ & $0.481 \pm 0.104$ \\
IFN- $\gamma /$ TGF- $\beta 1$ & $0.029 \pm 0.017$ & $0.059 \pm 0.024$ & $0.093 \pm 0.033^{*}$ \\
\hline
\end{tabular}

* Significant difference $(p<0.05)$ between the NI group and infected (MT or BT) groups. 


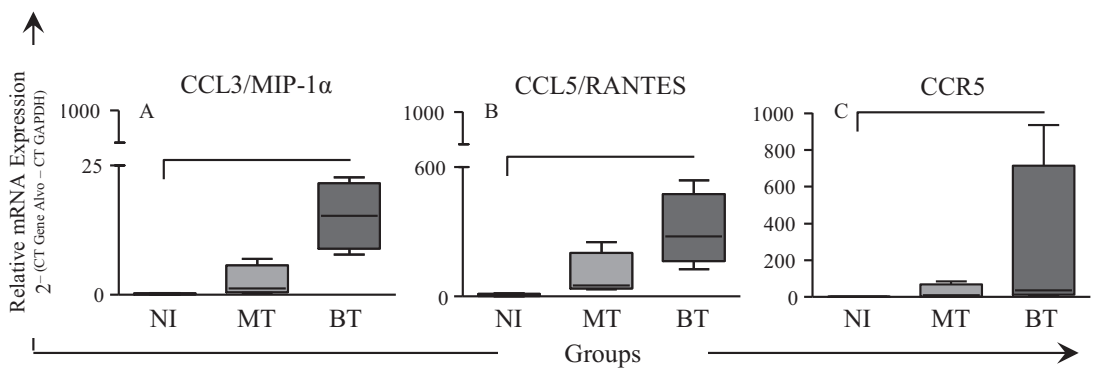

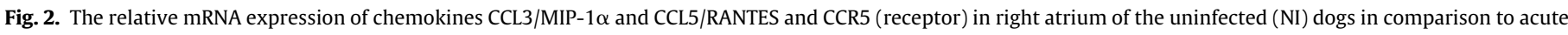

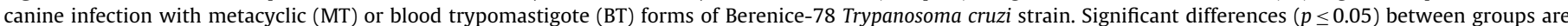
indicated by connecting lines.

\subsection{Chemokine mRNA expression profiles in dogs experimentally infected with MT and BT forms}

We also analyzed the relative mRNA expression of the chemokines CCL3/MIP-1 $\alpha$ and CCL5/RANTES and CCR5 receptor in cardiac tissue of dogs. We observed an increase in the relative mRNA expression of CCL3/MIP-1 $\alpha$ and CCL5/RANTES (Fig. 2A and B), as well as its CCR5 receptor (Fig. 2C) in the RA of dogs infected with the BT form when compared to the NI group.
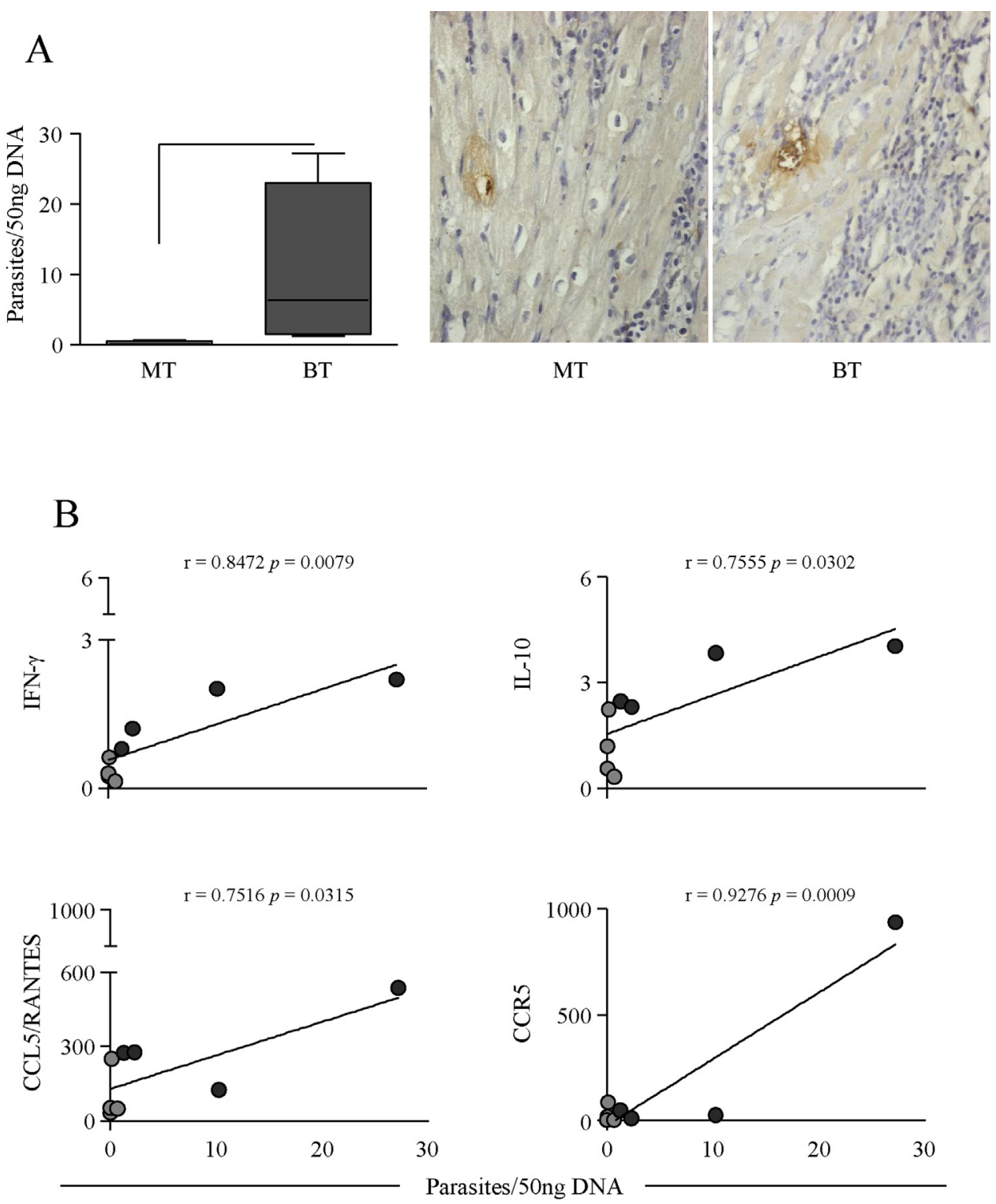

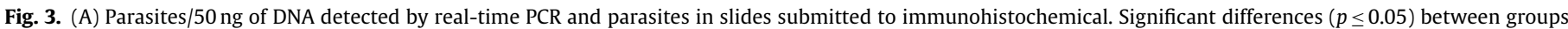

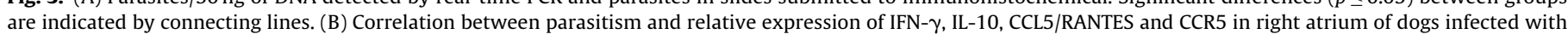
metacyclic (MT); or blood trypomastigote (BT); forms of Berenice-78 Trypanosoma cruzi strain. Spearman correlation indexes $(r$ and $p$ values) are shown on the graphs. 


\subsection{Quantification of cardiac parasitism and the correlation with cytokines, chemokines, and CCR5 receptor}

T. cruzi DNA was quantified by real-time PCR. We found an increase in the number of $T$. cruzi DNA copies in cardiac samples of dogs infected with the BT form as compared to the MT group (Fig. 3A). We also evaluated the correlation of parasitism in relation to the mRNA expression of cytokines, CCL3/MIP- $1 \alpha$, CCL5/RANTES and CCR5 receptor during acute $T$. cruzi infection (Fig. 3B). Our data showed a positive correlation between heart parasitism and the cytokines IFN- $\gamma$ and IL-10, the chemokine CCL5/RANTES and CCR5 receptor.

\section{Discussion}

In the present study, we investigated the cytokine, chemokine, and CCR5 profiles as well as tissue parasitism during the acute phase of Chagas disease in dogs experimentally infected with the MT or BT forms of Berenice-78 T. cruzi strain. The two infective forms of the parasite employed in this study are known to induce distinct immune responses in vitro and in vivo (Brener and Gazzinelli, 1997; Camargo et al., 1997a). These immunological differences may help to explain why the BT form, but not epimastigotes or the MT form, is a potent stimulator of pro-inflammatory cytokines and nitric oxide synthesis by murine macrophages. This factor can be related to glycoproteins such as glycosylphosphatidylinositol (GPI) as studies have shown that selective chemical removal of this unsaturated fatty acid in PI moiety of GPI-anchored mucin-like glycoproteins (tGPI mucins) from MT forms is sufficient for a drastic ( $\sim 100$ - to 1000 -fold) reduction in the ability of this molecule to activate macrophages (Camargo et al., 1997b; Almeida et al., 2000). Also, the GPI-anchor derived from BT and amastigote forms may act as an adjuvant molecule that promotes inflammation at the site of parasitic infection and possibly the myocarditis induced during experimental and human Chagas disease (Ropert and Gazzinelli, 2000).

In this study, the analysis of relative mRNA expression of cytokines, CCL3/MIP-1 $\alpha$, CCL5/RANTES, and CCR5 in cardiac tissue revealed an evident exacerbation of these immune mediators in dogs experimentally infected with BT form. When analyzing the ratio of mRNA expression of pro-inflammatory versus immunomodulatory cytokines, we found higher IL-12p40/IL-10 and IL-12p40/TGF- $\beta 1$ ratios in dogs infected with the MT form. This result may indicate the importance of the cytokine IL-12p40 in the control of $T$. cruzi infection during the acute phase, which may be related to the low parasitism in animals infected with the MT form. In fact, during the acute phase, dogs infected with MT exhibited better control of the parasitism as compared to BT-infected dogs. A study of $T$. cruzi infection in IL-12-deprived mice indicated that IL-12 is essential for the generation of parasite-antigen-specific $T$ lymphocytes that produce IFN- $\gamma$, which in turn activates response mechanisms against the parasite and is involved in lymphocyte recruitment to the site of infection (Galvão Da Silva et al., 2003).

On the other hand, dogs infected with BT form showed higher expression levels of the pro-inflammatory cytokines IL-12p40, TNF- $\alpha$, IFN- $\gamma$, and IL- 4 , which is a type II cytokine, as well as the immunomodulatory cytokines IL-10 and TGF- $\beta 1$. However, the increase of immunomodulatory cytokines did not control the expression of pro-inflammatory cytokines and did no lead to the control of parasite replication. Analysis of the ratios of pro-inflammatory versus immunomodulatory cytokines showed a greater relative mRNA expression of pro-inflammatory cytokines (mainly TNF- $\alpha$ and IFN- $\gamma$ ) in dogs infected with the BT form. Therefore, our results suggest that the BT form may lead to an exacerbation of the immune response and uncontrolled tissue parasitism. Research in a hamster model suggested that high cardiac parasitism could be the underlying reason for increased expression of TNF- $\alpha$, IFN- $\gamma$, and IL-10 cytokines, as well as the chemokine CCL3/MIP-1 $\alpha$ (Bilate et al., 2008).

Guedes et al. (2009) analyzed the supernatant culture of peripheral blood mononuclear cells from dogs chronically infected with T. cruzi that developed the cardiac form of the disease. Their results showed high production of IFN- $\gamma$ and TNF- $\alpha$ with little or no IL10 during the acute phase. Moreover, IL-10 production by T-cells promotes T. cruzi control and protection against acute myocarditis in a mouse model (Roffe et al., 2011). Some studies have shown that TGF- $\beta$ increased in the circulation of patients infected with $T$. cruzi (Araujo-Jorge et al., 2002; Silva et al., 1991) and its participation during the process of $T$. cruzi cell host invasion (Ming et al., 1995). Studies in CCR5 ${ }^{-1-}$ mice showed their higher susceptibility to infection; when CCL3/MIP-1 $\alpha$, CCL5/RANTES, and CCR5 receptor were blocked, intense inflammation and cardiac fibrosis were observed (Calzada et al., 2001; Talvani et al., 2004; Marino et al., 2004; Machado et al., 2005; Hardison et al., 2006; Roffe et al., 2010; Sullivan et al., 2011). Although these previous studies in a mouse model showed the importance of these parameters, it appears that in canine infection by the BT form, the relative mRNA expression of cytokines, CCL3/MIP-1 $\alpha$, CCL5/RANTES, and CCR5 receptor do not help to control parasitism.

We observed a positive correlation between heart parasitism and expression levels of IFN- $\gamma$, IL-10, CCL5/RANTES, and CCR5 receptor. The correlation showed increased relative mRNA expression of IFN- $\gamma$ and IL-10, which may be an immunomodulatory response. However, a previous study found an increased inflammatory process in dogs infected by BT form (Vieira et al., 2009). This seems to suggest that in an attempt to control parasites, there is increased expression of IFN- $\gamma$. However, we also found an increased expression of IL-10. Thus, the expression of cytokines, which is a consequence of the high parasitism, may trigger the clinical condition of severe infection with $T$. cruzi. Also there was an increase in the relative expression of CCL5/RANTES and its CCR5 receptor, and the correlation was mainly due to the higher cardiac parasitism observed in dogs infected with the BT form. Was demonstrated that CCL5/RANTES is crucial for the induction of cellular migration; treatment with Met-RANTES clearly diminished the infiltration of T-cells and fibronectin deposition, critical aspects of chagasic cardiomyopathy, in the hearts of $T$. cruzi - infected mice (Marino et al., 2004). In contrast with this finding, in $T$. cruzi - infected rats the chemokines CCL3/MIP- $1 \alpha$ and CCL5/RANTES were relevant, but not essential, for control of the infection (Roffe et al., 2010). Therefore, the dog may also have a particular immune response mechanism against infection by $T$. cruzi, considering that we observed distinct profiles when MT and BT forms were employed to infect the animals.

This work showed that infection with the BT form of $T$. cruzi led to an increased immune response when compared to infection with the MT form. The dogs infected with BT showed increased relative mRNA expression of cytokines, CCL3/MIP- $1 \alpha$, CCL5/RANTES, and CCR5. However, this profile did not promote parasite control, indicating that infection with BT is more severe than the MT form and the infective form may influence the immunopathological aspects of Chagas disease. We plan to expand our research to better understand the role of neutrophils and macrophage and T-cells subsets, as well as toll-receptors, in the cardiac inflammatory process.

\section{Acknowledgements}

This work received financial support from the Rede Mineira de Bioterismo (Fundação de Amparo à Pesquisa do Estado de Minas Gerais), Universidade Federal de Ouro Preto and research fellowships from Conselho Nacional de Desenvolvimento Científico e Tecnológico (Carneiro, C.M.; Reis, A.B.) and 
Coordenação de Aperfeiçoamento de Pessoal de Nível Superior (Souza, S.M.).

\section{References}

Almeida, I.C., Camargo, M.M., Procopio, D.O., Silva, L.S., Mehlert, A., Travassos, L.R., Gazzinelli, R.T., e Ferguson, M.A.J., 2000. Highly purified glycosylphosphatidylinositols from Trypanosoma cruzi are potent proinflammatory agents. EMBO J. $19,1476-1485$

Andrade, L.O., Andrews, N.W., 2005. The Trypanosoma cruzi-host-cell interplay: location, invasion, retention. Nat. Rev. Microbiol. 3, 819-823.

Araujo-Jorge, T.C., Waghabi, M.C., Hasslocher-Moreno, A.M., Xavier, S.S., Higuchi Mde, L., Keramidas, M., Bailly, S., Feige, J.J., 2002. Implication of transforming growth factor-beta1 in Chagas disease myocardiopathy. J. Infect. Dis. 186, 1823-1828.

Bahia, M.T., Tafuri, W.L., Caliari, M.V., Veloso, V.M., Carneiro, C.M., Coelho, G.L., Lana, M., 2002. Comparison of Trypanosoma cruzi infection in dogs inoculated with blood or metacyclic trypomastigotes of Berenice-62 and Berenice-78 strains via intraperitoneal and conjunctival routes. Rev. Soc. Bras. Med. Trop. 35, 339-345.

Bilate, A.M., Teixeira, P.C., Ribeiro, S.P., Brito, T., Silva, A.M., Russo, M., Kalil, J., CunhaNeto, E., 2008. Distinct outcomes of Trypanosoma cruzi infection in hamsters are related to myocardial parasitism, cytokine/chemokine gene expression, and protein expression profile. J. Infect. Dis. 198, 614-623.

Brener, Z., Gazzinelli, R.T., 1997. Immunological control of Trypanosoma cruzi infection and pathogenesis of Chagas' disease. Int. Arch. Allergy Immunol. 114, $103-110$

Calzada, J.E., Nieto, A., Beraun, Y., Martin, J., 2001. Chemokine receptor CCR5 polymorphisms and Chagas' disease cardiomyopathy. Tissue Antigens 58, 154-158.

Camargo, M.M., Almeida, I.C., Pereira, M.E., Ferguson, M.A., Travassos, L.R., e Gazzinelli, R.T., 1997a. Glycosylphosphatidylinositol-anchored mucin-like glycoproteins isolated from Trypanosoma cruzi trypomastigotes initiate the synthesis of proinflammatory cytokines by macrophages. J. Immunol. 158, 5890-5901.

Camargo, M.M., Andrade, A.C., Almeida, I.C., Travassos, L.R., Gazzinelli, R.T., 1997b. Glycoconjugates isolated from Trypanosoma cruzi but not from Leishmania species membranes trigger nitric oxide synthesis as well as microbicidal activity in IFN-gamma-primed macrophages. J. Immunol. 159, 6131-6139.

Carneiro, C.M., Martins-Filho, O.A., Reis, A.B., Veloso, V.M., Araujo, F.M., Bahia, M.T., de Lana, M., Machado-Coelho, G.L., Gazzinelli, G., Correa-Oliveira, R., Tafuri, W.L., 2007. Differential impact of metacyclic and blood trypomastigotes on parasitological, serological and phenotypic features triggered during acute Trypanosoma cruzi infection in dogs. Acta Trop. 101, 120-129.

Chagas, C., 1909. Nova tripanossomíase humana, Estudos sobre a morfologia e o ciclo evolutivo do Schizotrypanum cruzi n. gen., n. sp., ajente etiolójico de nova entidade mórbida do homem. Mem. Inst. Oswaldo Cruz 1, 159-218.

COBEA, 2006. Colégio Brasileiro de Experimentação Animal, www.cobea.org.br

Costa, G.C., Costa Rocha, M.O., Moreira, P.R., Menezes, C.A., Silva, M.R., Gollob, K.J., Dutra, W.O., 2009. Functional IL-10 gene polymorphism is associated with Chagas disease cardiomyopathy. J. Infect. Dis. 199, 451-454.

Coura-Vital, W., Carneiro, C.M., Martins, H.R., de Lana, M., Veloso, V.M., TeixeiraCarvalho, A., Bahia, M.T., Correa-Oliveira, R., Martins-Filho, O.A., Tafuri, W.L., Reis, A.B., 2008. Trypanosoma cruzi: immunoglobulin isotype profiles during the acute phase of canine experimental infection with metacyclic or blood trypomastigotes. Exp. Parasitol. 120, 269-274.

Cummings, K.L., Tarleton, R.T., 2003. Rapid quantitation of Trypanosoma cruzi in host tissue by real-time PCR. Mol. Biochem. Parasitol. 129, 53-59.

Cunha-Neto, E., Rizzo, L.V., Albuquerque, F., Abel, L., Guilherme, L., Bocchi, E., Bacal, F., Carrara, D., Ianni, B., Mady, C., Kalil, J., 1998. Cytokine production profile of heart-infiltrating T cells in Chagas' disease cardiomyopathy. Braz. J. Med. Biol. Res. 31, 133-137.

Galvão Da Silva, A.P., Jacysyn, J.F., De Almeida Abrahamsohn, I., 2003. Resistant mice lacking interleukin-12 become susceptible to Trypanosoma cruzi infection but fail to mount a T helper type 2 response. Immunology 108, 230-237.

Gascon, J., Bern, C., Pinazo, M.J., 2010. Chagas disease in Spain, the United States and other non-endemic countries. Acta Trop. 115, 22-27.

Gazzinelli, R.T., Oswald, I.P., Hieny, S., James, S.L., Sher, A., 1992. The microbicidal activity of interferon-gamma-treated macrophages against Trypanosoma cruzi involves an L-arginine-dependent, nitrogen oxide-mediated mechanism inhibitable by interleukin-10 and transforming growth factor-beta. Eur. J. Immunol. 22, 2501-2506.

Guedes, P.M., Veloso, V.M., Afonso, L.C., Caliari, M.V., Carneiro, C.M., Diniz, L.F., Marques-da-Silva, E.A., Caldas, I.S., Do Valle Matta, M.A., Souza, S.M., Lana, M., Chiari, E., Galvao, L.M., Bahia, M.T., 2009. Development of chronic cardiomyopathy in canine Chagas disease correlates with high IFN-gamma, TNF-alpha, and low IL-10 production during the acute infection phase. Vet. Immunol. Immunopathol. 130, 43-52.

Hansen, D.S., Villacres-Eriksson, M., Akerblom, L., Hellman, U., Segura, E., Carlomagno, M., Morein, B., 1998. An immunoaffinity-purified Trypanosoma cruzi antigen suppresses cellular proliferation through a TGF-beta-mediated mechanism. Scand. J. Immunol. 47, 509-516.

Hardison, J.L., Wrightsman, R.A., Carpenter, P.M., Kuziel, W.A., Lane, T.E., Manning, J.E., 2006. The CC chemokine receptor 5 is important in control of parasite replication and acute cardiac inflammation following infection with Trypanosoma cruzi. Infect. Immun. 74, 135-143.
Jackson, Y., Getaz, L., Wolff, H., Holst, M., Mauris, A., Tardin, A., Sztajzel, J., Besse, V., Loutan, L., Gaspoz, J.M., Jannin, J., Albajar Vinas, P., Luquetti, A., Chappuis, F., 2010. Prevalence, clinical staging and risk for blood-borne transmission of Chagas disease among Latin American migrants in Geneva, Switzerland. PLoS Negl. Trop. Dis. 4, e592.

Kaufmann, A., Salentin, R., Gemsa, D., Sprenger, H., 2001. Increase of CCR1 and CCR5 expression and enhanced functional response to MIP-1 alpha during differentiation of human monocytes to macrophages. J. Leukoc. Biol. 69, 248-252.

Lana, M., Chiari, E., 1986. Comparative biological characterization of Berenice and Berenice-78 strains of Trypanosoma cruzi isolated from the same patient at different times. Mem. Inst. Oswaldo Cruz 81, 247-253.

Lijnen, P.J., Petrov, V.V., Fagard, R.H., 2000. Induction of cardiac fibrosis by transforming growth factor-beta(1). Mol. Genet. Metab. 71, 418-435.

Machado, F.S., Koyama, N.S., Carregaro, V., Ferreira, B.R., Milanezi, C.M., Teixeira, M.M., Rossi, M.A., Silva, J.S., 2005. CCR5 plays a critical role in the development of myocarditis and host protection in mice infected with Trypanosoma cruzi. J. Infect. Dis. 191, 627-636.

Mack, M., Cihak, J., Simonis, C., Luckow, B., Proudfoot, A.E., Plachy, J., Bruhl, H., Frink, M., Anders, H.J., Vielhauer, V., Pfirstinger, J., Stangassinger, M., Schlondorff, D., 2001. Expression and characterization of the chemokine receptors CCR2 and CCR5 in mice. J. Immunol. 166, 4697-4704.

Marino, A.P., da Silva, A., dos Santos, P., Pinto, L.M., Gazzinelli, R.T., Teixeira, M.M. Lannes-Vieira, J., 2004. Regulated on activation, normal T cell expressed and secreted (RANTES) antagonist (Met-RANTES) controls the early phase of Trypanosoma cruzi-elicited myocarditis. Circulation 110, 1443-1449.

Martin, D.L., Postan, M., Lucas, P., Gress, R., Tarleton, R.L., 2007. TGF-beta regulates pathology but not tissue CD8+ T cell dysfunction during experimental Trypanosoma cruzi infection. Eur. J. Immunol. 37, 2764-2771.

Michailowsky, V., Silva, N.M., Rocha, C.D., Vieira, L.Q., Lannes-Vieira, J., Gazzinelli, R.T., 2001. Pivotal role of interleukin-12 and interferon-gamma axis in controlling tissue parasitism and inflammation in the heart and central nervous system during Trypanosoma cruzi infection. Am. J. Pathol. 159, 1723-1733.

Ming, M., Ewen, M.E., Pereira, M.E., 1995. Trypanosome invasion of mammalian cells requires activation of the TGF beta signaling pathway. Cell 82, 287-296.

Ramirez, L.E., Lages-Silva, E., Soares Junior, J.M., Chapadeiro, E., 1993. Experimental hamster infection by Trypanosoma cruzi: the chronic phase. Rev. Soc. Bras. Med. Trop. 26, 253-254.

Roffe, E., Oliveira, F., Souza, A.L., Pinho, V., Souza, D.G., Souza, P.R., Russo, R.C., Santiago, H.C., Romanha, A.J., Tanowitz, H.B., Valenzuela, J.G., Teixeira, M.M., 2010. Role of CCL3/MIP-1alpha and CCL5/RANTES during acute Trypanosoma cruzi infection in rats. Microbes Infect. 12, 669-676.

Roffe, E., Rothfuchs, A.G., Santiago, H.C., Marino, A.P., Ribeiro-Gomes, F.L., Eckhaus, M., Antonelli, L.R., Murphy, P., 2011. M. IL-10 limits parasite burden and protects against fatal myocarditis in a mouse model of Trypanosoma cruzi infection. J. Immunol. 188, 649-660.

Ropert, C., Gazzinelli, R.T., 2000. Signaling of immune system cells by glycosylphosphatidylinositol (GPI) anchor and related structures derived from parasitic protozoa. Curr. Opin. Microbiol. 3, 395-403.

Ropert, C., Ferreira, L.R., Campos, M.A., Procopio, D.O., Travassos, L.R., Ferguson, M.A. Reis, L.F., Teixeira, M.M., Almeida, I.C., Gazzinelli, R.T., 2002. Macrophage signaling by glycosylphosphatidylinositol-anchored mucin-like glycoproteins derived from Trypanosoma cruzi trypomastigotes. Microbes Infect. 4, 1015-1025.

Rottman, J.B., Ganley, K.P., Williams, K., Wu, L., Mackay, C.R., Ringler, D.J., 1997. Cellular localization of the chemokine receptor CCR5. Correlation to cellular targets of HIV-1 infection. Am. J. Pathol. 151, 1341-1351.

Silva, J.S., Twardzik, D.R., Reed, S.G., 1991. Regulation of Trypanosoma cruzi infections in vitro and in vivo by transforming growth factor beta (TGF-beta). J. Exp. Med. 174, 539-545.

Soares, M.B., Pontes-De-Carvalho, L., Ribeiro-Dos-Santos, R., 2001. The pathogenesis of Chagas' disease: when autoimmune and parasite-specific immune responses meet. An. Acad. Bras. Cienc. 73, 547-559.

Strasen, J., Williams, T., Ertl, G., Zoller, T., Stich, A., Ritter, O., 2013. Epidemiology of Chagas disease in Europe: many calculations, little knowledge. Clin. Res. Cardiol.

Sullivan, N.L., Eickhoff, C.S., Zhang, X., Giddings, O.K., Lane, T.E., Hoft, D.F., 2011. Importance of the CCR5-CCL5 axis for mucosal Trypanosoma cruzi protection and B cell activation. J. Immunol. 187, 1358-1368.

Talvani, A., Rocha, M.O., Ribeiro, A.L., Correa-Oliveira, R., Teixeira, M.M., 2004. Chemokine receptor expression on the surface of peripheral blood mononuclear cells in Chagas disease. J. Infect. Dis. 189, 214-220.

Teixeira, M.M., Gazzinelli, R.T., Silva, J.S., 2002. Chemokines, inflammation and Trypanosoma cruzi infection. Trends Parasitol. 18, 262-265.

Vieira, P.M., Francisco, A.F., de Souza, S.M., Malaquias, L.C., Reis, A.B., Giunchetti, R.C., Veloso, V.M., de Lana, M., Tafuri, W.L., Carneiro, C.M., 2009. Trypanosoma cruzi: serum levels of nitric oxide and expression of inducible nitric oxide synthase in myocardium and spleen of dogs in the acute stage of infection with metacyclic or blood trypomastigotes. Exp. Parasitol. 121, 76-82.

Vivier, E., Tomasello, E., Baratin, M., Walzer, T., Ugolini, S., 2008. Functions of natural killer cells. Nat. Immunol. 9, 503-510.

Wallace, J.A., Miller, L., Beavis, A., Baptista, C.A., 2013. Chagas disease: a proposal for testing policy for solid-organ transplant in the United States. Prog. Transplant. 23, 272-277.

World Health Organization (WHO), www.who.int/mediacentre/factsheets/ fs340/en/index.html (accessed in 2013) 2013. Chagas Disease (American Trypanosomiasis).

Yoshida, N., 2006. Molecular basis of mammalian cell invasion by Trypanosoma cruzi. An. Acad. Bras. Cienc. 78, 87-111. 